\title{
AN ANALYSIS OF SALES INFORMATION SYSTEM AND COMPETITIVE ADVANTAGE (Study Case of UD. Citra Helmet)
}

\author{
Hendra Alianto; Santo FernandiWijaya; FikriArlan \\ Information Systems Department, School of Information Systems, Bina Nusantara University \\ Jl. K. H. Syahdan No-9, Jakarta 11480, Indonesia \\ hendraalianto@yahoo.com, santofwijaya@yahoo.com, crackerrap20@yahoo.com
}

\begin{abstract}
Business development in this era of globalization leads companies to use information system in running business relationship by changing the traditional way of working in non-integrated information systems into integrated information systems. The intended use of the integrated information system will improve the effective and efficient way of working, such as the availability of information in real-time, accurate and informative for decision-making for the benefit of operational activities, as well as decision-making for strategic interests and the company's business development. Especially with the application of sales information system, it will improve the company's performance and will affect the competitiveness of companies, which can ultimately increase the maximum profit. However, in reality it is not easy to implement the integrated information system, because it is influenced by the customs, culture and mindset of the user company. It is necessary for running system analysis activity and building an integrated information system by concerning into the needs of users, management, customers and stakeholders. The implementation of integrated information system will increase productivity and achieve the effectiveness and efficiency level of company's operations, through the analysis of sales information system will affect the competitiveness of companies.
\end{abstract}

Keywords: Sales Information System Analysis

\section{INTRODUCTION}

Traditional way of working by using nonintegrated information systems will cause inhibition in the information flow in decision making, for operational purposes, as well as strategic interest in the development of the company's business. The company needs to implement integrated information system to obtain information that is relatively fast, precise and accurate for decision-making, with the hope of influencing the way of working, improving the smooth flow of information in the pattern level business value chain, and eventually the company may have competitive advantage compared with company that still apply the system manually.

This research is expected to provide insight to the efforts in order to increase the competitive advantage for the company, with the efforts of analysis and implementation of sales information system that fit the needs of users, management, customers and stakeholders, which finally will improve the competitive advantage.

The running system analysis, especially the sale of information system includes process evaluation of business sales, order status and monitoring inventory.

Analyzing the running sales process to get a picture of the sales process and then perform sales information system design according to user needs, management, customers, and stakeholders, which ultimately can improve performance at UD. Citra Helmet.

Provide applicable understanding towards knowledge to solve problems that occur in the company in appropriate way to the needs of the company's business and add knowledge to see any problems that occur in every company with the right solution in solving the problem.

By conducting the research based on the research aims, it is expected that it will give benefit to the company. The benefit are such as knowing the needs of the company in accordance with the business processes of sales information systems, generating analysis and sales information system that can develop and recognize the level of program application needs, which will be built in order to help company in controlling sales activities. So, it is in line with the strategic development of the company's business.

\section{METHOD}

In The methodology of this study is a case study approach, analysis and evaluation and also literature 
study of the company's documents that related to the use of technology and information systems that exist in the company. The preparation of this methodology is by using the analysis and design of information system in building integrated information system using methodology of FAST (Framework for the Application of System Thinking), which consists of the scope definition, problem analysis, requirements analysis, logical design, decision analysis, physical design and integration, construction and testing, installation and delivery. The methodology is then processed and adapted in line with the conditions of the research object so that the methodological approaches may be more appropriate.

To obtain the processed data, there are three data collection techniques, namely literature study, which is done by reading articles or writings related to the topic of research through books, journals, and the internet; interviews, which will be conducted with the management and people related to the topic of research; observation, which will be a direct observation on the related parts to the research. This research is required to determine the running business processes, the availability and necessary of information, and the application of technology and the observation of performance of those associated with the business process and the questionnaire, which is a technique of data collection is done by giving a set of written questions.

\section{Information System}

System information is an organized combination of people, hardware, software, communication network and data resources that collect, transform and distribute information within an organization [1].

Information system is a collection of interrelated component that collect, process, store, and provide output information needed to complete business tasks [2]. Completing business tasks is usually a "problem" that has been discussed previously.

From the above understanding it can be concluded that information system is a combination of related components, which are designed to collect, store, process and provide output information needed by the user in an organization.

Ref. [2] states that the used concepts in object orientation is wrapping all the data that describe people, places, events in a container, which is the object itself.

Based on the above definition, it can be concluded that system is a collection of components that implement the requirements, functions and interfaces of the modeling. System is a group of related components, working together to achieve a common goal by receiving input and producing output in an orderly transformation process. It can be concluded that system is a collection of components that are interconnected to implement requirements, functions and interfaces of the mutual support modeling to achieve a goal. And object-oriented analysis and design is an activity to determine the problem domain and then look for the logical problem solving in a container, which is the object itself.

\section{Object Oriented Concept}

In developing the system, object oriented approach can be used [3]. The oriented approach itself is an approaching system development that views information system as a collection of objects that interact and work together to accomplish tasks.

Unified Modeling Language (UML) is a standard set of construction model and specially developed notation for object-oriented development [3]. By using UML, the analysis and the last user can describe and understand the specific diagrams used in system development projects. Component model systems uses unified modeling language consists of seven diagrams. Class diagram gives an overview of the structure and description of classes, packages, and object and relationship to one another such as inheritance and association. Activity diagram is an overview of the various users (or system) activity, people who perform each activity and the sequential flow of the activity. Symbols used are use case diagram, class diagram, activity diagram, sequence diagram. System sequence diagram is a diagram that shows the sequence of messages between external actor and system during the use case or scenario.

\section{Sales Information System}

The revenue cycle is a set or collection of business activities and related information process operation associated with the provision of goods and services to customers and collecting cash in payment of the sales transaction [4]. The main goal is to provide product, place and right time.

There are four basic business activities that are performed in the revenue cycle [4], namely: (1) Sales Order. (2) Delivery. (3) Billing and accounts receivable. (4) Cash receipts. From the description, it can be concluded that the sales information is an activity and the activity in the provision of goods and services to customers.

\section{RESULT AND DISCUSSION}

\section{Problem}

The problem faced by the UD Citra Helmet company is the delay of information flow of sales activities, such as the difficulty to monitor order status, customer billing, inventory status, sales report, due to the working way of non-integrated information systems (manual). It makes the obtained information is less valid and difficult to exchange information for 
decision-making to the benefit of the operational and strategic interests of company.

\section{Troubleshooting}

To provide solutions to the company's problems, it is necessary to do analysis of sales information system and to design an integrated information system that will be developed by building an application program. Proposed design of information systems sales are as follows:

Design of UML Diagram - Use Case Diagram Proposed:

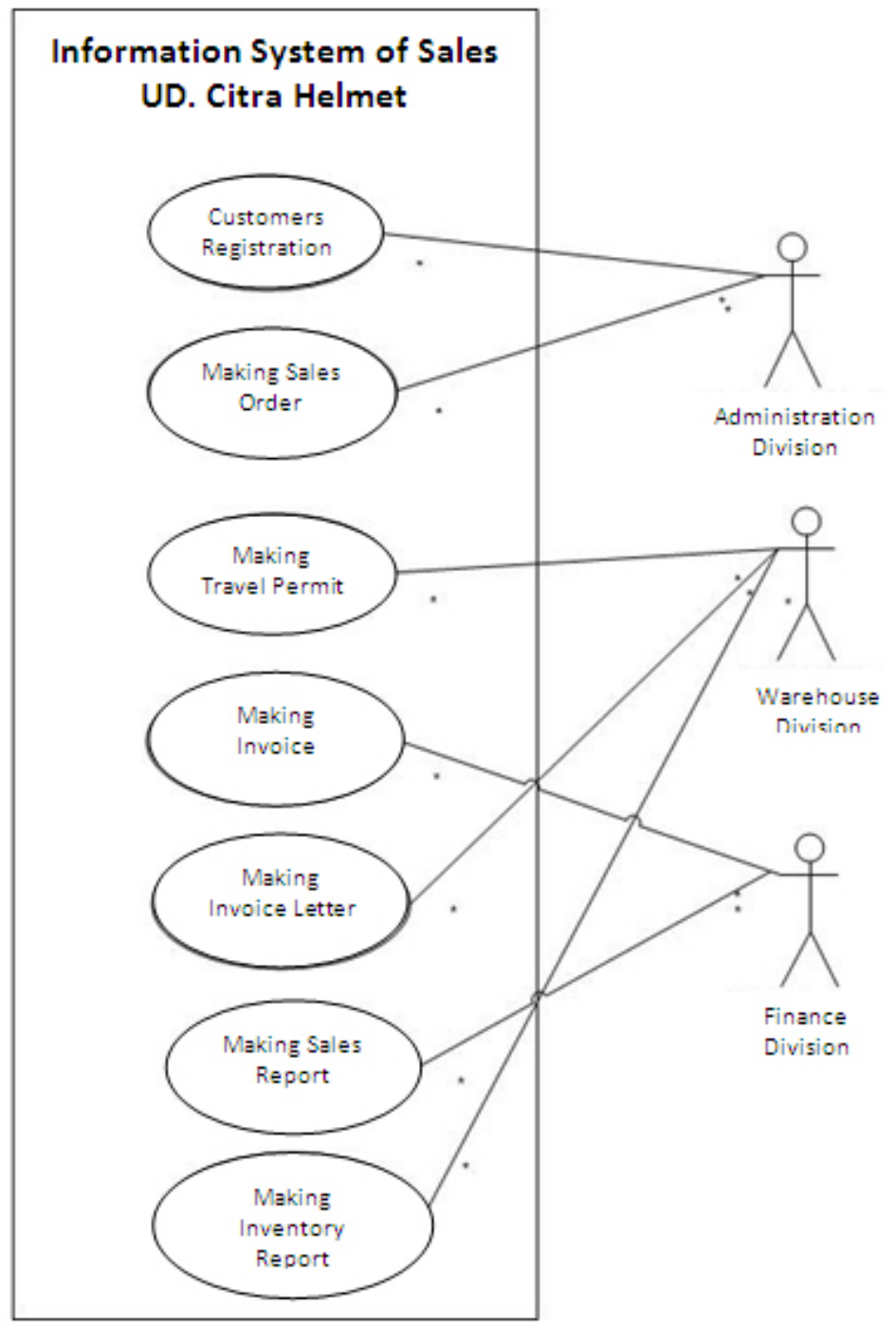

Fig. 1: Proposed Use Case Diagram 


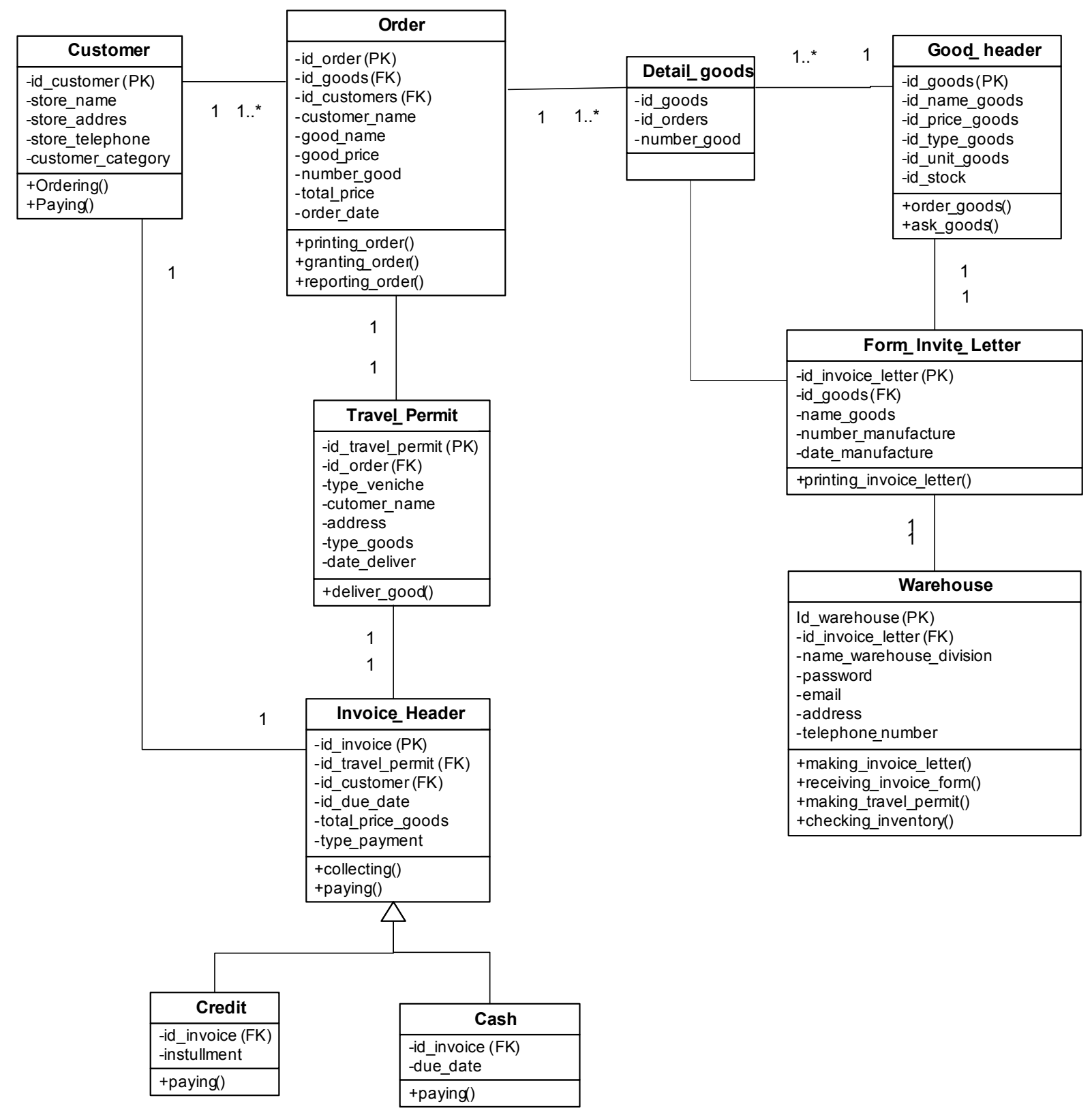

Fig. 2: Proposed Class Diagram 


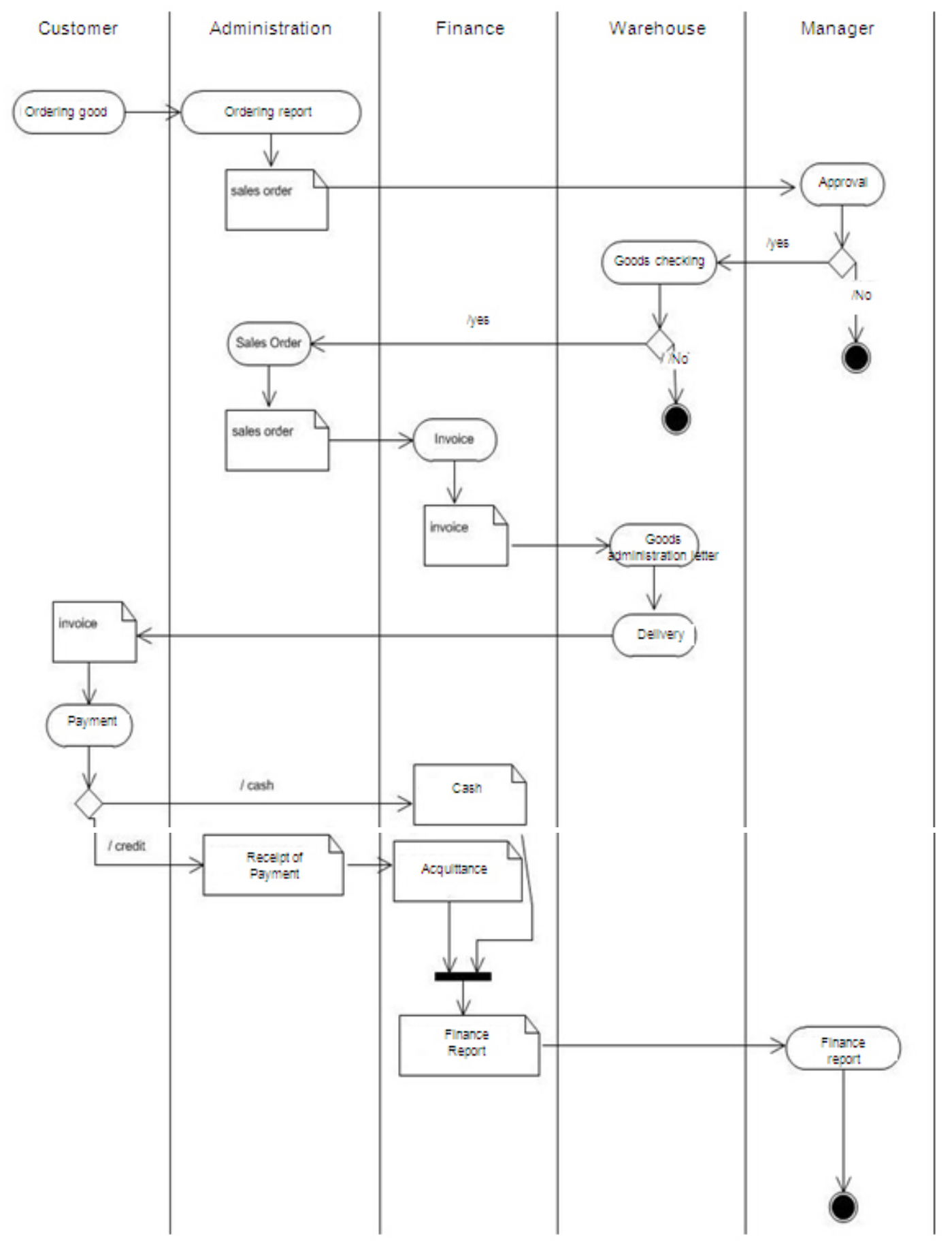

Fig. 3: Proposed Activity Diagram 


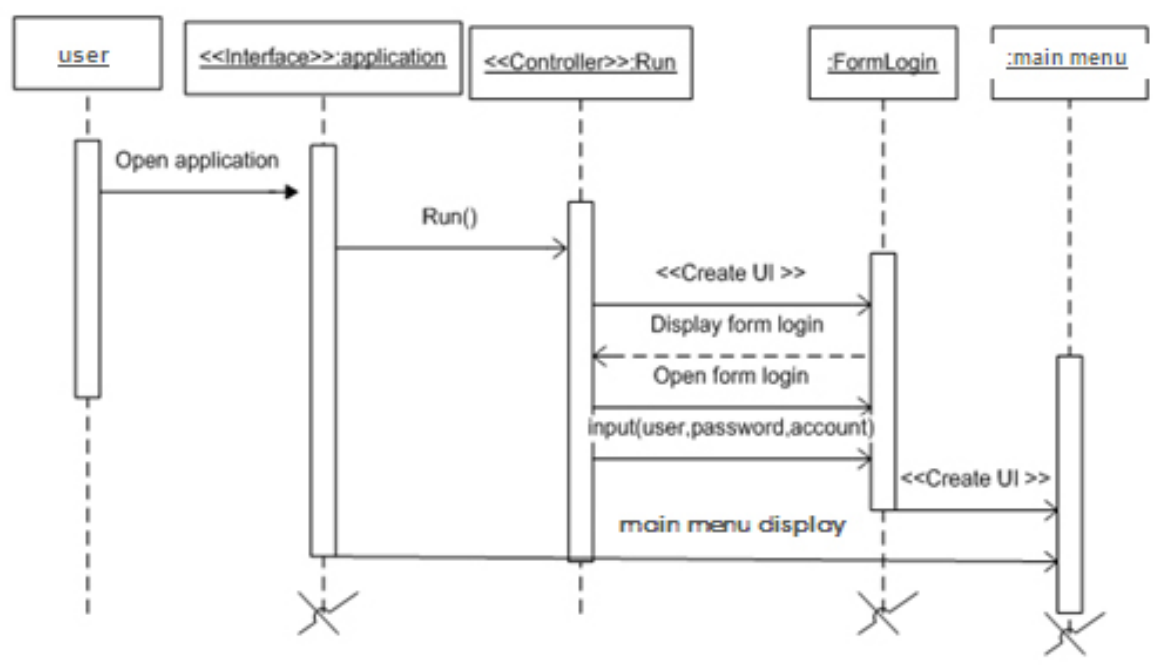

Fig 4: Sequence Diagram of Main Menu

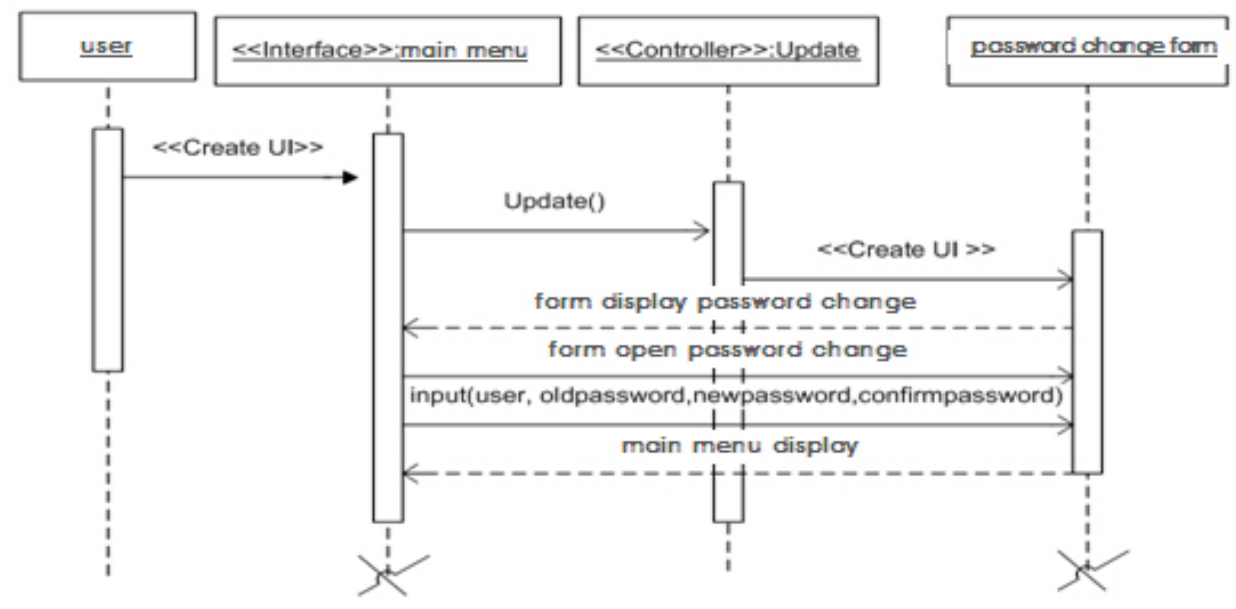

Fig 5: Proposed Sequence Diagram of Changing Password

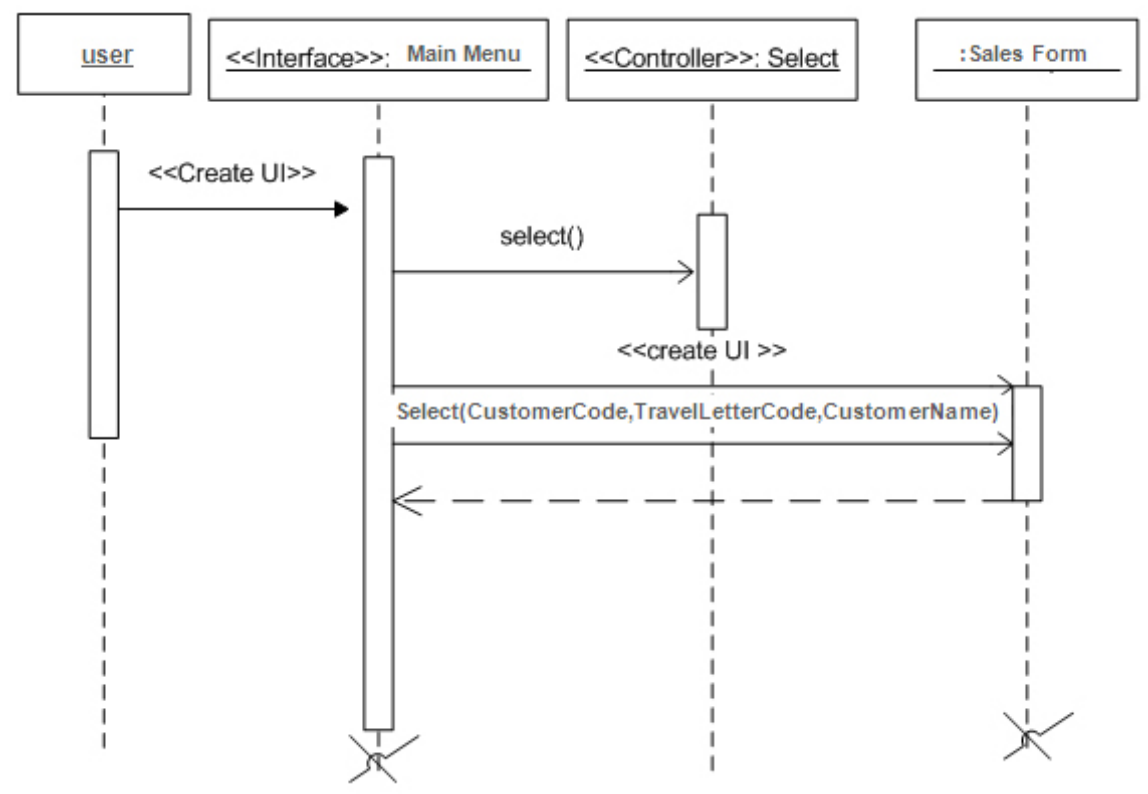

Fig 6: Sequence Diagram of Sales 


\section{CONCLUSION}

Based on the research results of the analysis of sales information system, it can be useful to improve the efficiency of the inner workings of sales business processes, by knowing the status order, inventory status information in real-time and facilitate the presentation of sales reports accurately and up to date. With the sales information system, it will have an impact in improving the performance of the company, which ultimately may provide the company's competitiveness. However, the audit of making better and more optimal provision of competent technology resources and the availability of human resources of running computerized system will ensure SOP systems and procedures are working properly.

Availability of online and real-time information is needed to provide information to managers and $\mathrm{CEO}$ in making their decision. It is necessary to create development step of related information system. Therefore, strategic planning is needed to maximize the application of integrated information system with the ERP system acceptance in the direction of a webbased application programs. With web-application program, the work is more efficient, especially for managers and CEO level to monitor operations and make decisions based on the obtained online-andmobile information that does not depend on the place, time and distance.

\section{REFERENCES}

[1] Kenneth C. Laudon, Jane P. Laudon, Management Information Systems: Managing the Digital Firm. 9th Edition, New Jersey: Pearson Prentice Hall, 2006.

[2] James A. O'Brien, and George Marakas, Introduction to Information Systems, 12th Edition, New York: The McGraw-Hill Companies, Inc, 2005.

[3] John W. Satzinger, Robert B. Jackson, Stephen D Burd, Object-oriented analysis \& design with the unified process, Thomson Course Technology, 2005.

[4] Romney, Marshall, Steinbart, Paul, Accounting information systems. 10th Edition, Pearson Prentice Hall, 2006. 